\title{
The use of capecitabine in daily practice: a study on adherence and patients' experiences
}

\author{
This article was published in the following Dove Press journal: \\ Patient Preference and Adherence \\ 18 October 2012 \\ Number of times this article has been viewed
}

\author{
Lonneke Timmers' \\ Eleonora L Swart' \\ Christel CLM Boons' \\ Dirk Mangnus' \\ Peter M van de Ven ${ }^{2}$ \\ Godefridus J Peters ${ }^{3}$ \\ Epie Boven ${ }^{3}$ \\ Jacqueline G Hugtenburg' \\ 'Department of Clinical Pharmacology \\ and Pharmacy, ${ }^{2}$ Department of \\ Epidemiology and Biostatistics, \\ ${ }^{3}$ Department of Medical Oncology, \\ VU University Medical Center, \\ Amsterdam, The Netherlands
}

Correspondence: Lonneke Timmers Department of Clinical Pharmacology and Pharmacy, VU University Medical Center, De Boelelaan III7, 108I HV Amsterdam, The Netherlands

Tel +3I 204442938

Fax +31 204442858

Email l.timmers@vumc.nl
Background: Adherence to pharmacological therapy is a complex and multifactorial issue that can substantially alter the outcome of treatment. Especially when using long-term medication, cancer patients have adherence rates similar to those of patients with other diseases. The consequences of poor adherence are poor health outcomes and increased health care costs. Only few studies have focused on the use of oral anticancer agents in daily practice. Information about the reasons for nonadherence is essential for the development of interventions that may improve adherence. This report presents the CAPER-capecitabine protocol, which is designed to study the adherence to capecitabine and the influence of patient attitudes towards medication and self-reported side effects. Furthermore, the relationships between patient characteristics, disease characteristics, side effects, quality of life, patient beliefs and attitudes towards disease and medication, dose adjustments, reasons for discontinuation, and plasma concentration of three of the main metabolites, including the active compound 5-fluorouracil, will be explored.

Methods: In this multicenter, prospective, observational cohort study, 90 patients aged 18 years or older starting treatment with capecitabine will be included and followed for a period up to five cycles. The main study parameters are adherence, patient attitudes towards medication, and the number and grade of patient-reported side effects. At baseline and during week 2 of cycles 1, 3 and 5, patients will be asked to donate blood and fill out a questionnaire. Blood samples will be analyzed for plasma concentration of the metabolites, $5^{\prime}$-deoxy-5-fluorouridine, 5 -fluorouracil, and $\alpha$-fluoro- $\beta$-alanine. The CAPER-capecitabine trial is closely related to the CAPER-erlotinib trial.

Discussion: The aim of the present study is to get more insight into patient experiences with the use of capecitabine in daily practice and the various aspects that govern adherence. We hypothesize that patient attitudes towards medication and the side effects experienced play an important role in the way patients use capecitabine. We expect that our findings will be useful for health care professionals in developing interventions to support patients in improving adherence and persistence with the use of capecitabine.

Keywords: capecitabine, medication adherence, patients' experiences, medical oncology, oral antineoplastic agents

\section{Background}

Intravenous administration is an important route for pharmacological treatment of cancer. Over the last decade, a growing number of oral substances have been introduced in cancer treatment. Most patients prefer oral use of anticancer agents as long as it does not compromise the outcome of treatment. ${ }^{1-3}$ In addition, the overall costs of oral treatment are often lower than those of intravenous therapy. ${ }^{4-6}$ However, with the use of oral medication at home, the issue of adherence needs to be considered. 


\section{Adherence}

Adherence to oral pharmacological therapy is a complex and multifactorial issue that can substantially alter the outcome of therapy. ${ }^{7,8}$ Adherence (synonymous with compliance) has recently been defined by the International Society for Pharmacoeconomics and Outcome Research as the extent to which a patient acts in accordance with the prescribed interval and dose of a drug regimen. ${ }^{9}$ A patient is optimally adherent if no doses are missed, no extra doses are taken, and no doses are taken in the wrong quantity or at the wrong time. Adherence is measured over a period of time and reported as the adherence rate, which is the percentage of dose taken in relation to what was prescribed..$^{10}$ There are several methods used to measure adherence, including selfreports, pill counts, electronic monitoring systems, analyses of pharmacy dispensing records, and assessment of blood or urine samples. There is no golden standard measurement and all methods have limitations. ${ }^{10,11}$ The major limitation of measuring adherence is the so-called Hawthorne effect, ie, the monitoring of adherence itself influences adherence, because the awareness of patients that adherence is being monitored may influence their behavior. Adherence rates for many chronic drug therapies range between $35 \%$ and $70 \%{ }^{7,12}$ The consequences of poor adherence are poor health outcomes and increased health care costs. ${ }^{7}$

\section{Adherence in oncology}

Cancer patients are generally thought to have higher adherence rates than other patients because they are highly motivated by the gravity of their disease. ${ }^{13,14}$ However, cancer patients appear to have similar adherence rates to those of patients with other diseases..$^{10,15,16}$ Treatment duration plays a role in adherence to the regimen. When the medication is continued over a longer period of time, patients become less adherent. ${ }^{17}$ The measurement of adherence with medication that is used in complex cyclic schedules with stop periods and many individual adjustments during treatment, as often occurs in oncology, is challenging, since this is more difficult than the measurement of medication used on a regular daily basis.

In oncology, adherence has been studied mainly in two subpopulations, both using long-term medication. In the first population, adherence of patients with breast cancer to adjuvant hormonal therapy has been the subject of several studies. ${ }^{10}$ Reported adherence rates range from $50 \%$ to $98 \%{ }^{14,17,18}$ Several studies concerning adherence with oral medication have been published in the second population, being patients with chronic myeloid leukemia. ${ }^{16,19,20}$
Nonadherence has been associated with a poorer response to imatinib. ${ }^{16,19}$ Noens et al have shown that patients with a suboptimal response had higher percentages of imatinib not taken $(23 \%)$ than those with optimal response $(7 \%) .{ }^{16}$ Marin et al have also demonstrated that there was a strong correlation between adherence rate and response in patients with chronic myeloid leukemia. ${ }^{19}$ Adherence was the only critical factor for achieving a molecular response. The results of these studies cannot be translated directly to adherence with other oral anticancer drugs, because their use differs mainly with respect to duration of treatment and the toxicity generated by the treatment.

Another frequently overlooked problem is over adherence, which may be more an issue in oncology than in other diseases and may lead to substantially increased toxicity. ${ }^{11}$ In the study by Nilsson et al, 30\% of cancer patients had an oversupply of their medication. ${ }^{15}$

Medical oncologists and hematologists may not always consider the issue of adherence. As yet, suboptimal adherence may prove to be the greatest barrier to the efficacy of the various newly introduced oral anticancer agents. ${ }^{10,19}$

\section{Causes of nonadherence}

Several factors are associated with nonadherence. These include patient variables, such as demographic factors and patients' beliefs, and disease variables, various aspects of treatment regimens, side effects, and quality of life.

The commonsense model of self-regulation developed by Leventhal et $\mathrm{al}^{21}$ is a theoretical model for understanding patient perceptions of illness. ${ }^{22}$ According to the commonsense model of self-regulation, patient perception of and beliefs about their illness are important factors in their reactions and behavior to health threats. Illness perceptions can easily be measured with the Brief Illness Perceptions Questionnaire. ${ }^{23}$ Another factor which has been shown to influence adherence is patient beliefs about the medication, often measured with the Beliefs about Medicines Questionnaire (BMQ). ${ }^{24}$

Few studies have focused on patients' reasons for not adhering to oral anticancer agents. Eliasson et al have reported that finding ways to deal with side effects leads to better adherence in patients with chronic myeloid leukemia. ${ }^{25}$ In clinical trials, adverse events are generally reported by clinicians using, eg, the National Cancer Institute Common Terminology Criteria for Adverse Events. ${ }^{26}$ Basch et al have shown the value of patient-reported adverse events in cancer patients, which better reflect their daily health status. ${ }^{27-29}$ 


\section{Capecitabine}

Capecitabine $\left(\mathrm{Xeloda}^{\circledR}\right)$ is an oral anticancer agent, which was introduced in 2001. Capecitabine is an oral prodrug for 5 -fluorouracil (5-FU). It is one of a number or oral formulations of 5-FU (UFT, S-1, doxifluridine, capecitabine) which were developed to mimic continuous infusions (defined as one week or longer), which are associated with longer survival than the commonly used intravenous bolus administration schedules (eg, the Roswell Park and Mayo schedules). ${ }^{30,31}$ These schedules were standard until early 2000. Continuous administration of 5-FU leads to prolonged exposure to low concentrations of 5-FU which has been shown both in vitro and in vivo to be more effective than short exposure to high concentrations. Capecitabine is registered in Europe for the treatment of advanced colorectal cancer, gastric cancer, and breast cancer. ${ }^{32}$ It is also registered for the adjuvant treatment of patients following surgery of stage III (Dukes' stage C) colon cancer, either given alone or combined with either oxaliplatin or irinotecan. Capecitabine is commonly used in a 3 -week treatment cycle, with an intake of capecitabine twice daily for 14 days followed by a 7-day rest period.

The most common side effects of capecitabine are gastrointestinal disorders (especially diarrhea, nausea, vomiting, abdominal pain, and stomatitis), hand-foot syndrome (palmar-plantar erythrodysesthesia), fatigue, asthenia, anorexia, cardiotoxicity, increased renal dysfunction in those with pre-existing compromised renal function, and thrombosis/embolism. ${ }^{32}$

Several studies have demonstrated that capecitabine is as effective as intravenous 5-FU. Borner et al have reported in a crossover study showing that patients preferred oral capecitabine to intravenous 5-FU. ${ }^{3}$ However, using a similar study design, Pfeiffer et al observed that patients prefer the regimen with the lowest toxicity and that the route of administration is of minor importance. ${ }^{33}$ The use of capecitabine has also been the subject of pharmacoeconomic analyses. Several studies have shown the cost-effectiveness of treatment with capecitabine as compared with that of 5-FU in patients with colorectal cancer or compared with intravenous taxane-based therapy in patients with breast cancer. ${ }^{34-36}$

Adherence with capecitabine has been the subject of a few studies. In a review published by Ruddy et al, only one study concerning adherence with capecitabine was included. ${ }^{10}$ Partridge et al reported at the 2008 American Society of Clinical Oncology annual meeting that $76 \%$ of 161 breast cancer patients took at least $80 \%$ of their prescribed capecitabine doses, as measured by an electronic monitoring system during a six-cycle period. ${ }^{37}$ Winterhalder et al assessed adherence to capecitabine with self-reporting in diaries. ${ }^{38}$ They observed that $91 \%$ of patients were adherent with all doses. A similar rate has been reported by Simons et al using an electronic monitoring system. ${ }^{39}$

\section{Pharmacokinetics}

Capecitabine is rapidly and extensively absorbed through the gastrointestinal wall as an intact molecule, and rapidly metabolized to 5-FU via a three-step enzymatic cascade. First, it is metabolized to $5^{\prime}$-deoxy-5-fluorocytidine ( $5^{\prime}$-DFCR), thereafter to $5^{\prime}$-deoxy-5-fluorouridine ( $5^{\prime}$-DFUR), and subsequently to the active compound 5-FU. 5-FU is metabolized to dihydrofluorouracil, 5-fluoro-ureido-propionic acid, and $\alpha$-fluoro- $\beta$-alanine (FBAL, see Figure 1$).{ }^{40}$ When taken with food at a dose of $1250 \mathrm{mg} / \mathrm{m}^{2}$ on day 14 , peak plasma concentrations $\left(\mathrm{C}_{\max }\right)$ of capecitabine, $5^{\prime}$-DFCR, 5'-DFUR, 5-FU, and FBAL are 4.7, 3.1, 12.1, 1.0, and $5.5 \mu \mathrm{g} / \mathrm{mL}$, respectively. Peak plasma concentrations are reached approximately 1.5-3.5 hours after administration. The elimination half-life $\left(\mathrm{t}_{1 / 2}\right)$ of capecitabine and its metabolites in plasma is short, ie, $1-3$ hours. ${ }^{32}$

There is considerable variability in the plasma concentrations of capecitabine and its metabolites. ${ }^{41}$ However, it should be realized that activation to 5-FU takes place in the tumor. The enzyme involved in the final conversion to 5-FU (thymidine phosphorylase), is found in tumor tissues, but also in normal tissues, albeit usually at lower levels; 5-FU concentrations in plasma can be considered as a reflection of the release from tumors and not as a reliable pharmacokinetic parameter for capecitabine. Moreover, it has been demonstrated that 5-FU has a relatively long tissue half-life, both in animal systems and in patients. ${ }^{42}$ With use at home, variations in plasma concentration may also be influenced by adherence with capecitabine. It is hypothesized that a higher adherence rate will lead to higher plasma concentrations which, in turn, may lead to better survival rates.

Intake of food prior to or together with administration of capecitabine results in a longer time taken to reach peak plasma concentrations and a lower $\mathrm{C}_{\max }$ of capecitabine and its metabolites. The manufacturer advises in the European Public Assessment Report that "the tablets should be swallowed with water within the 30 min after a meal". ${ }^{32,43}$ Renal impairment has no effect on the pharmacokinetics of capecitabine or 5-FU, but leads to an increased exposure of $5^{\prime}$-DFUR and FBAL and therefore requires dose modification of capecitabine. ${ }^{44}$ Twelves et al have reported that plasma concentrations of capecitabine, 5'-DFUR, 5-FU, and FBAL were, in general, higher in patients with liver dysfunction, 


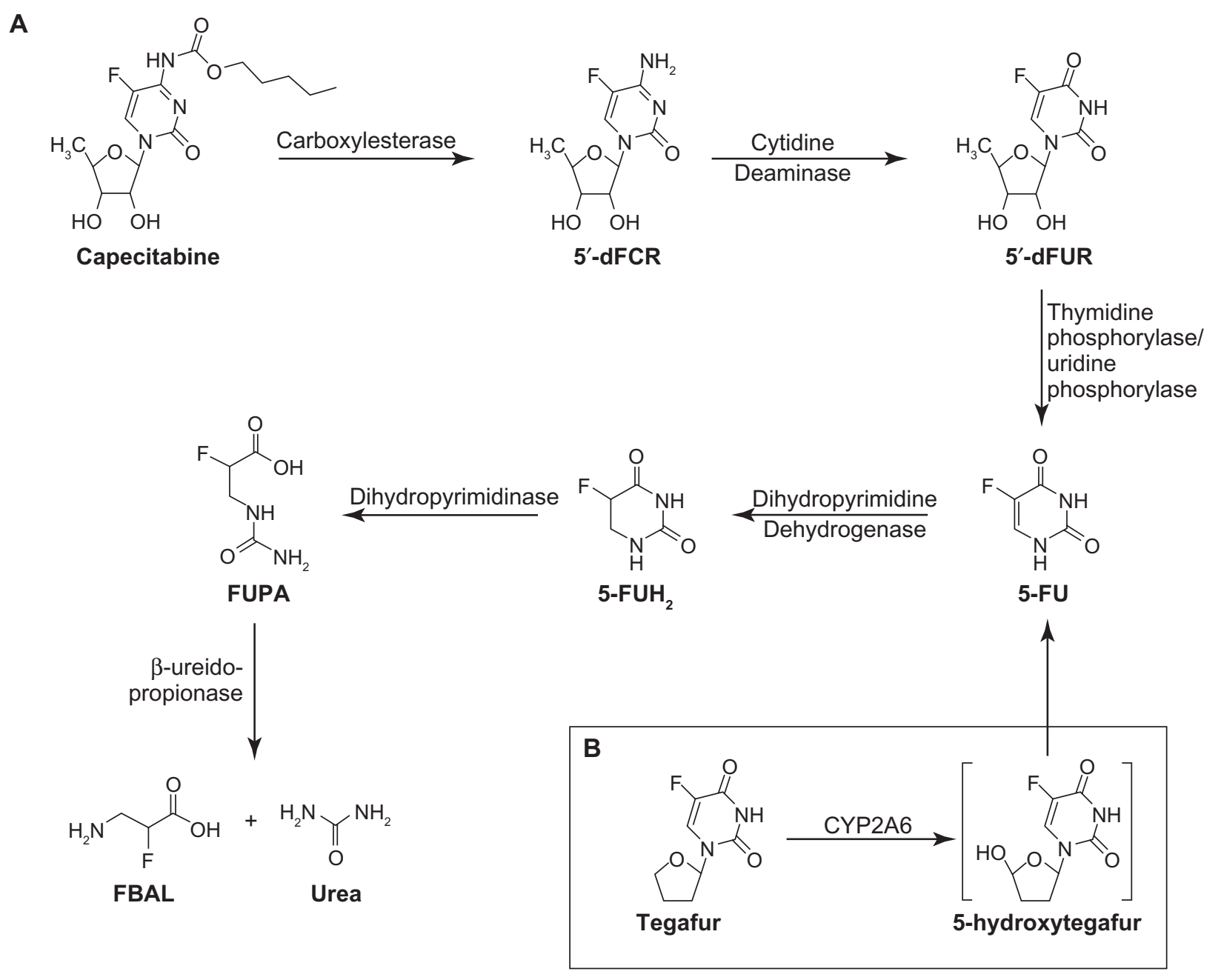

Figure I Metabolic pathways for capecitabine and tegafur. (A) Capecitabine is converted into active metabolite in situ by thymidine phosphorylase or uridine phosphorylase. Further 5 -fluorouracil catabolism is initiated by dihydropyrimidine dehydrogenase, eventually yielding FBAL, a catabolite implicated in the etiology of hand-foot syndrome. (B) Tegafur is activated by cytochrome P450 2A6, forming 5-hydroxytegafur, an unstable intermediate which spontaneously converts to 5-fluorouracil.

Reprinted by permission from Yen-Revollo JL, Goldberg RM, McLeod HL. Can inhibiting dihydropyrimidine dehydrogenase limit hand-foot syndrome caused by fluoropyrimidines? Clin Cancer Res. 2008;14:8-13.

Abbreviations: FBAL, and $\alpha$-fluoro- $\beta$-alanine; 5'-dFUR, 5'-deoxy-5-fluorouridine; FUPA, 5 -fluoro-ureido-propionic acid; 5'-dFCR; 5 '-deoxy-5-fluorocytidine.

while the opposite was found for $5^{\prime}$-DFCR. ${ }^{45}$ There were no clinical relevant differences in the adverse effects between patients with and without hepatic dysfunction.

Ethnicity may also influence the pharmacokinetics of capecitabine and its metabolites. In Caucasian patients, higher plasma concentrations of FBAL were measured than in Japanese patients. ${ }^{46}$

Genetic factors may affect the efficacy and toxicity of capecitabine related to the activity of the enzymes involved in its metabolism. Mutations and polymorphisms in dihydropyrimidine dehydrogenase, resulting in decreased degradation of 5-FU (from capecitabine) is associated with severe toxicity. $47-49$ Other mutations and polymorphisms may result in altered activity of cytidine deaminase or carboxylesterase, thereby influencing the efficacy and toxicity of capecitabine..$^{50,51}$
A small increase in plasma concentration of capecitabine and 5'-DFCR may occur when given concurrently with an antacid containing aluminum or magnesium hydroxide. This has not been shown for 5'-DFUR, 5-FU, and FBAL. ${ }^{52}$

The various factors described above have to be taken into account when the relationship between plasma concentrations and adherence rates is studied in patients using capecitabine. The mutations and polymorphisms will not be evaluated in the present study, but may be part of future research.

Several studies on the efficacy, side effects, and pharmacokinetics of capecitabine have shown that plasma concentrations of 5'-DFUR, 5-FU, and FBAL are related to efficacy and toxicity. Gieschke et al have observed that the $\mathrm{C}_{\text {max }}$ of 5 '-DFUR was positively associated with survival and that the area under the concentration-time curve (AUC) of 5-FU 
was negatively associated with time to disease progression. ${ }^{53}$ This is in contrast with data on 5-FU in which a higher AUC of 5-FU was associated with a longer survival. ${ }^{54}$ In general, in 5-FU administration schedules, a clear relationship was found for the AUC of 5-FU and both hematological and gastrointestinal toxicity. ${ }^{55,56}$ In patients with grade 3-4 diarrhea, the AUC of FBAL was proportionately increased. Grade 3-4 hyperbilirubinemia was positively associated with the AUC of 5-FU and negatively associated with the $\mathrm{C}_{\max }$ of FBAL. ${ }^{57}$ Plasma concentrations of capecitabine and $5^{\prime}$-DFCR were not related to toxicity. ${ }^{53}$

Capecitabine can cause hand-foot syndrome, which is most likely associated with accumulation of the breakdown product FBAL, given that in formulations in which dihydropyrimidine dehydrogenase is inhibited, no handfoot syndrome was observed. ${ }^{40}$ Because side effects may be a reason for nonadherence, the plasma concentrations of 5'-DFUR, 5-FU, and FBAL are analyzed in this study.

The primary objective in this study is adherence in patients with cancer starting capecitabine and the influence of patients' attitudes and side effects on adherence. The second part of this study contains a validation study of the adherence measurements and an explorative study on the relationships between the following parameters: patient characteristics, disease characteristics, side effects, quality of life, patients' beliefs and attitudes towards disease and medicines, adherence, dose adjustments, and plasma 5'-DFUR, 5-FU, and FBAL concentrations.

\section{Materials and methods Study design}

This is a prospective observational multicenter cohort study in which cancer patients starting on treatment with capecitabine will be followed for up to five 3-weekly cycles. The trial will end when the last patient has been followed for five cycles. The CAPER-capecitabine trial (NTR2324) is closely related to the CAPER-erlotinib trial (NTR1830) which is being performed simultaneously. ${ }^{58}$ The protocol was approved by the medical ethics review board of the VU University Medical Center, Amsterdam, The Netherlands.

\section{Recruitment and consent}

Patients are to be recruited by the departments of medical oncology from 10 hospitals in The Netherlands. After a patient and physician have decided on treatment with capecitabine, the patient will be informed about the study and receive written information to take home. Within 2 days, the researcher contacts the patient by phone to inform him/her further about the study and to ask for his/her consent. The patient will be asked to sign the informed consent form.

\section{Inclusion criteria}

Patients on treatment in one of the participating hospitals starting with the use of capecitabine can be included. Patients younger than 18 years and those with insufficient knowledge of the Dutch language are excluded. According to the sample size calculation (see Statistical analysis) a total number of 90 patients are to be enrolled.

\section{Measurements}

Several methods are used to determine the variables. Most information is collected directly from patients, ie, they will fill out questionnaires and donate blood samples. Furthermore, medical information is retrieved from the patients' file.

\section{Questionnaires}

Patients will be asked to fill out four questionnaires spread over a 14-week period. The first questionnaire $(t=0)$ contains questions about patient characteristics, comedication, side effects, quality of life, and patients' beliefs and attitude towards disease and medication. In week 2 of cycles 1 , 3 and 5, patients are asked to fill out an elaborate questionnaire containing questions determining the adherence behavior, side effects, dose adjustment, comedication, quality of life, and their beliefs and attitude towards the disease and medication. Discontinuation and reasons for discontinuation are to be canvassed in a short questionnaire when a patient discontinues capecitabine treatment prematurely.

The questionnaires include the following items:

- The MARS (Medication Adherence Report Scale) questionnaire ${ }^{59,60}$ contains statements about adherence behavior, and the nature and grade of patient-reported side effects on a five-point scale.

- Quality of life measured with the Short Form (SF)-12 Health Survey. ${ }^{61,62}$ The SF-12 is a short version of the SF-36 and is a validated method for measurement of quality of life.

- Attitude towards disease is measured using the Brief Illness Perception Questionnaire. ${ }^{23}$ The Brief Illness Perception Questionnaire is a validated method measuring attitudes towards disease.

- Beliefs and attitudes towards medicines are measured with the validated BMQ questionnaire. ${ }^{24}$ The BMQ is divided into two parts, ie, the BMQ general and the BMQ specific. The BMQ general measures patient beliefs and 
attitudes towards medicines in general, whereas the BMQ specific is specific for capecitabine.

- Patient characteristics, ie, date of birth, gender, and socioeconomic status.

- Dose adjustments by the patient, with dose adjustments introduced by the physician to be derived from the patient file.

- Comedication.

- Discontinuation and reasons for discontinuation. Discontinuation will also be determined from the patient file.

\section{Patient file}

The following items are derived from the patient treatment file:

- Disease characteristics, including disease stage and line of treatment

- Dose adjustments

- Discontinuation and reasons for discontinuation.

\section{Patient files-pharmacy records-pill count method}

This pill count method will take into account the cyclic dosing regimen with stop periods and individual adjustments made by the physician, such as postponing a cycle or dose changes. Patients will be contacted by the researcher by telephone to count their remaining pills at that moment. The dispensing records of the pharmacies used by the patient will be assessed. Patients will be asked whether they have returned pills at the pharmacy or disposed of pills in any other way. The actual number of pills used will be calculated from this information (dispensings minus adjustments minus pill count) and compared with the prescribed number of pills, as registered in the patient's medical file, to calculate the adherence rate.

\section{Blood samples}

Before the start of treatment with capecitabine, baseline blood samples are collected. In the second week of cycles 1, 3, and 5, blood samples are collected. At these visits, patients are asked when they ate their last meal and at what time they took their last capecitabine medication. The timing of collection of the blood sample will be recorded. The blood samples will be analyzed for plasma concentrations of 5'-DFUR, 5-FU, and FBAL using a validated liquid chromatography/tandem mass spectrometry method. Capecitabine is most commonly used in a 3-week treatment cycle, with an intake of capecitabine twice daily for 14 days followed by a 7 -day rest period. ${ }^{32}$ In the event of a longer rest period, the number of additional rest days will be added to the schedule to make sure the measurements always take place in the second week of each cycle.

\section{Statistics}

The primary determinant of interest is patient attitudes towards anticancer drugs at the start of therapy. We will test the hypothesis that the probability of nonadherence does not differ between those with a negative attitude and those with a positive attitude towards capecitabine, against the onesided alternative that nonadherence is higher in those with a negative attitude. Based on previous studies, the percentage of patients who are nonadherent with drug therapy is estimated at $35 \%$ for patients with a negative attitude towards capecitabine, and at $10 \%$ for patients with a positive attitude towards capecitabine. To test the hypothesis at a significant level of 0.05 , we need 33 patients with a positive attitude and 33 patients with a negative attitude to achieve $80 \%$ power. To reach the required number of evaluable patients, a total number of 90 patients will be included in the study. The statistical analyses will be performed using SPSS version 20.0 (SPSS Inc, Chicago, IL).

\section{Discussion}

The present study aims to obtain more insight into patient experiences with the use of capecitabine in daily practice. We expect variability in adherence among the general oncology population. This may be complicated by interpatient variability in pharmacokinetics. We hypothesize that patient attitudes towards anticancer drugs and side effects experienced play an important role in the way patients use capecitabine. Therefore, the relationship between attitude, self-reported side effects, and adherence is also defined as a main objective. To obtain more insight into other factors related to adherence and other aspects of use at home, the effects of the determinants are studied in an explorative manner. We expect that the present study will provide valuable knowledge on patient experiences with the use of capecitabine. This knowledge will be useful for health care professionals to develop specific interventions to support patients with the use of capecitabine in order to derive optimal benefit from the medication.

\section{Disclosure}

The authors received an unrestricted grant from Roche, The Netherlands, to perform this research. Otherwise, the authors declare that they have no competing interests in this work.

\section{Reference}

1. Fallowfield L, Atkins L, Catt S, et al. Patients' preference for administration of endocrine treatments by injection or tablets: results from a study of women with breast cancer. Ann Oncol. 2006;17:205-210. 
2. Liu G, Franssen E, Fitch MI, Warner E. Patient preferences for oral versus intravenous palliative chemotherapy. J Clin Oncol. 1997;15: $110-115$.

3. Borner M, Scheithauer W, Twelves C, Maroun J, Wilke H. Answering patients' needs: oral alternatives to intravenous therapy. Oncologist. 2001;6 Supp1 4:12-16.

4. Kruse GB, Amonkar MM, Smith G, Skonieczny DC, Stavrakas S. Analysis of costs associated with administration of intravenous singledrug therapies in metastatic breast cancer in a U.S. population. J Manag Care Pharm. 2008;14:844-857.

5. Twelves CJ. Xeloda in Adjuvant Colon Cancer Therapy (X-ACT) trial: overview of efficacy, safety, and cost-effectiveness. Clin Colorectal Cancer. 2006;6:278-287.

6. Ward SE, Kaltenthaler E, Cowan J, Marples M, Orr B, Seymour MT. The clinical and economic benefits of capecitabine and tegafur with uracil in metastatic colorectal cancer. Br J Cancer. 2006;95: 27-34.

7. Sabaté E. Adherence to Long-term Therapies: Evidence for Action. Geneva, Switzerland: World Health Organization; 2003.

8. Tebbi CK. Treatment compliance in childhood and adolescence. Cancer. 1993;71:3441-3449.

9. Cramer JA, Roy A, Burrell A, et al. Medication compliance and persistence: terminology and definitions. Value Health. 2008;11:44-47.

10. Ruddy K, Mayer E, Partridge A. Patient adherence and persistence with oral anticancer treatment. CA Cancer J Clin. 2009;59: 56-66.

11. Partridge AH, Avorn J, Wang PS, Winer EP. Adherence to therapy with oral antineoplastic agents. J Natl Cancer Inst. 2002;94:652-661.

12. Yeaw J, Benner JS, Walt JG, Sian S, Smith DB. Comparing adherence and persistence across 6 chronic medication classes. J Manag Care Pharm. 2009;15:728-740.

13. Klein CE, Kastrissios H, Miller AA, et al. Pharmacokinetics, pharmacodynamics and adherence to oral topotecan in myelodysplastic syndromes: a Cancer and Leukemia Group B study. Cancer Chemother Pharmacol. 2006;57:199-206.

14. Waterhouse DM, Calzone KA, Mele C, Brenner DE. Adherence to oral tamoxifen: a comparison of patient self-report, pill counts, and microelectronic monitoring. J Clin Oncol. 1993;11:1189-1197.

15. Nilsson JLG, Andersson K, Bergkvist A, Bjorkman I, Brismar A, Moen J. Refill adherence to repeat prescriptions of cancer drugs to ambulatory patients. Eur J Cancer Care (Engl). 2006;15:235-237.

16. Noens L, van Lierde MA, De Bock R, et al. Prevalence, determinants, and outcomes of nonadherence to imatinib therapy in patients with chronic myeloid leukemia: the ADAGIO study. Blood. 2009;113: 5401-5411.

17. Partridge AH, Wang PS, Winer EP, Avorn J. Nonadherence to adjuvant tamoxifen therapy in women with primary breast cancer. J Clin Oncol. 2003;21:602-606.

18. Ruddy KJ, Partridge AH. Adherence with adjuvant hormonal therapy for breast cancer. Ann Oncol. 2009;20:401-402.

19. Marin D, Bazeos A, Mahon F, et al. Adherence is the critical factor for achieving molecular responses in patients with chronic myeloid leukemia who achieve complete cytogenetic responses on imatinib. J Clin Oncol. 2010;28:2381-2388.

20. Wu EQ, Guerin A, Yu AP, Bollu VK, Guo A, Griffin JD. Retrospective real-world comparison of medical visits, costs, and adherence between nilotinib and dasatinib in chronic myeloid leukemia. Curr Med Res Opin. 2010;26:2861-2869.

21. Leventhal H, Diefenbach MA. The active side of illness cognition. In: Skelton JA and Croyle RT, editors. Mental representation in health and illness. New York, NY: Springer-Verlag; 1991:247-272.

22. McAndrew LM, Musumeci-Szabo TJ, Mora PA, et al. Using the common sense model to design interventions for the prevention and management of chronic illness threats: from description to process. Br J Health Psychol. 2008;13:195-204.

23. Broadbent E, Petrie KJ, Main J, Weinman J. The brief illness perception questionnaire. J Psychosom Res. 2006;60:631-637.
24. Horne R, Weinman J, Hankins M. The beliefs about medicines questionnaire: the development and evaluation of a new method for assessing the cognitive representation of medication. Psychology and Health. 1999;14: $1-24$.

25. Eliasson L, Clifford S, Barber N, Marin D. Exploring chronic myeloid leukemia patients' reasons for not adhering to the oral anticancer drug imatinib as prescribed. Leuk Res. 2011;35:626-630.

26. National Cancer Institute. Common Terminology Criteria for Adverse Events. Available from: http://ctep.cancer.gov/protocolDevelopment/ electronic_applications/docs/ctcaev3.pdf. Accessed August 4, 2012.

27. Basch E, Iasonos A, McDonough T, et al. Patient versus clinician symptom reporting using the National Cancer Institute Common Terminology Criteria for Adverse Events: results of a questionnaire-based study. Lancet Oncol. 2006;7:903-909.

28. Basch E, Jia X, Heller G, et al. Adverse symptom event reporting by patients vs clinicians: relationships with clinical outcomes. $J$ Natl Cancer Inst. 2009;101:1624-1632.

29. Basch $\mathrm{E}$. The missing voice of patients in drug-safety reporting. NEngl J Med. 2010;362:865-869.

30. Aprile G, Mazzer M, Moroso S, Puglisi F. Pharmacology and therapeutic efficacy of capecitabine: focus on breast and colorectal cancer. Anticancer Drugs. 2009;20:217-229.

31. Davies JM, Goldberg RM. First-line therapeutic strategies in metastatic colorectal cancer. Oncology (Williston Park). 2008;22:1470-1479.

32. European Medicines Agency. European Public Assessment Report. Xeloda Product Information. Available from: http://www.ema.europa. eu/ema/index.jsp?curl=pages/medicines/human/medicines/000316/ human_med_001157.jsp\&jsenabled=true. Accessed August 4, 2012.

33. Pfeiffer P, Mortensen JP, Bjerregaard B, et al. Patient preference for oral or intravenous chemotherapy: a randomised cross-over trial comparing capecitabine and Nordic fluorouracil/leucovorin in patients with colorectal cancer. Eur J Cancer. 2006;42:2738-2743.

34. Cassidy J, Douillard JY, Twelves C, et al. Pharmacoeconomic analysis of adjuvant oral capecitabine vs intravenous 5-FU/LV in Dukes' $\mathrm{C}$ colon cancer: the X-ACT trial. Br J Cancer. 2006;94:1122-1129.

35. Tse VC, Ng WT, Lee V, et al. Cost-analysis of XELOX and FOLFOX 4 for treatment of colorectal cancer to assist decision-making on reimbursement. BMC Cancer. 2011;11:288.

36. Rugo HS, Kohles J, Schulman KL. Cost comparison of capecitabine in patients with breast cancer. Am J Clin Oncol. 2010;33:550-556.

37. Partridge AH, Archer L, Kornblith AB, et al. Adherence and persistence with oral adjuvant chemotherapy in older women with early-stage breast cancer in CALGB 49907: adherence companion study 60104. J Clin Oncol. 2010;28:2418-2422.

38. Winterhalder R, Hoesli P, Delmore G, et al. Self-reported compliance with capecitabine: findings from a prospective cohort analysis. Oncology. 2011;80:29-33.

39. Simons S, Ringsdorf S, Braun M, et al. Enhancing adherence to capecitabine chemotherapy by means of multidisciplinary pharmaceutical care. Support Care Cancer. 2011;19:1009-1018.

40. Yen-Revollo JL, Goldberg RM, McLeod HL. Can inhibiting dihydropyrimidine dehydrogenase limit hand-foot syndrome caused by fluoropyrimidines? Clin Cancer Res. 2008;14:8-13.

41. Reigner B, Blesch K, Weidekamm E. Clinical pharmacokinetics of capecitabine. Clin Pharmacokinet. 2001;40:85-104.

42. Peters GJ, Lankelma J, Kok RM, et al. Prolonged retention of high concentrations of 5-fluorouracil in human and murine tumors as compared with plasma. Cancer Chemother Pharmacol. 1993;31:269-276.

43. Reigner B, Verweij J, Dirix L, et al. Effect of food on the pharmacokinetics of capecitabine and its metabolites following oral administration in cancer patients. Clin Cancer Res. 1998;4:941-948.

44. Poole C, Gardiner J, Twelves C, et al. Effect of renal impairment on the pharmacokinetics and tolerability of capecitabine (Xeloda) in cancer patients. Cancer Chemother Pharmacol. 2002;49:225-234.

45. Twelves C, Glynne-Jones R, Cassidy J, et al. Effect of hepatic dysfunction due to liver metastases on the pharmacokinetics of capecitabine and its metabolites. Clin Cancer Res. 1999;5:1696-1702. 
46. Reigner B, Watanabe T, Schuller J, et al. Pharmacokinetics of capecitabine (Xeloda) in Japanese and Caucasian patients with breast cancer. Cancer Chemother Pharmacol. 2003;52:193-201.

47. van Kuilenburg AB. Dihydropyrimidine dehydrogenase and the efficacy and toxicity of 5-fluorouracil. Eur J Cancer. 2004;40:939-950.

48. Hooiveld EAM, van Kuilenburg ABP, Haanen JBAG, Westermann AM. Ernstige toxiciteit na behandeling met capecitabine en fluorouracil ten gevolge van een partiële dihydropyrimidine-dehydrogenasedeficiëntie. [Severe toxicity after treatment with capecitabine and fluorouracil caused by partial dehydropyrimidine dehydrogenase deficiency]. Ned Tijdschr Geneeskd. 2004;148:626-628. Dutch.

49. Ciccolini J, Mercier C, Evrard A, et al. A rapid and inexpensive method for anticipating severe toxicity to fluorouracil and fluorouracil-based chemotherapy. Ther Drug Monit. 2006;28:678-685.

50. Mercier C, Dupuis C, Blesius A, et al. Early severe toxicities after capecitabine intake: possible implication of a cytidine deaminase extensive metabolizer profile. Cancer Chemother Pharmacol. 2008;63: 1177-1180.

51. Ribelles N, Lopez-Siles J, Sanchez A, et al. A carboxylesterase 2 gene polymorphism as predictor of capecitabine on response and time to progression. Curr Drug Metab. 2008;9:336-343.

52. Reigner B, Clive S, Cassidy J, et al. Influence of the antacid Maalox on the pharmacokinetics of capecitabine in cancer patients. Cancer Chemother Pharmacol. 1999;43:309-315.

53. Gieschke AR, Steimer JL, Reigner BG. Relationships between metrics of exposure to Xeloda ${ }^{\mathrm{TM}}$ and occurrence of adverse effects. Proc Am Soc Clin Oncol. 1998; 17:Abstr 861.

54. Fety R, Rolland F, Barberi-Heyob M, et al. Clinical impact of pharmacokinetically-guided dose adaptation of 5-fluorouracil: results from a multicentric randomized trial in patients with locally advanced head and neck carcinomas. Clin Cancer Res. 1998;4:2039-2045.
55. van Groeningen CJ, Pinedo HM, Heddes J, et al. Pharmacokinetics of 5-fluorouracil assessed with a sensitive mass spectrometric method in patients on a dose escalation schedule. Cancer Res. 1988;48: 6956-6961.

56. Codacci-Pisanelli G, Pinedo HM, Lankelma J, et al. Pharmacokinetics of bolus 5-fluorouracil: relationship between dose, plasma concentrations, area-under-the-curve and toxicity. J Chemother. 2005;17: 315-320.

57. Gieschke R, Burger HU, Reigner B, Blesch KS, Steimer JL. Population pharmacokinetics and concentration-effect relationships of capecitabine metabolites in colorectal cancer patients. Br J Clin Pharmacol. 2003;55:252-263.

58. Timmers L, Boons CCLM, Mangnus D, et al. The use of erlotinib in daily practice: a study on adherence and patients' experiences. $B M C$ Cancer. 2011;11:284.

59. Butler JA, Peveler RC, Roderick P, Horne R, Mason JC. Measuring compliance with drug regimens after renal transplantation: comparison of self-report and clinician rating with electronic monitoring. Transplantation. 2004; 77:786-789.

60. Horne R, Hankins M, Jenkins R. The Satisfaction with Information about Medicines Scale (SIMS): a new measurement tool for audit and research. Qual Health Care. 2001;10:135-140.

61. Aaronson NK, Muller M, Essink-Bot ML, et al. Translation, validation, and norming of the Dutch language version of the SF-36 health survey in community and chronic disease populations. J Clin Epidemiol. 1998;51: 1055-1068.

62. Hurst NP, Ruta DA, Kind P. Comparison of the MOS short form-12 (SF12) health status questionnaire with the SF36 in patients with rheumatoid arthritis. Br J Rheumatol. 1998;37:862-869.
Patient Preference and Adherence

\section{Publish your work in this journal}

Patient Preference and Adherence is an international, peer-reviewed, open access journal focusing on the growing importance of patient preference and adherence throughout the therapeutic continuum. Patient satisfaction, acceptability, quality of life, compliance, persistence and their role in developing new therapeutic modalities and compounds to

\section{Dovepress}

optimize clinical outcomes for existing disease states are major areas of interest. This journal has been accepted for indexing on PubMed Central. The manuscript management system is completely online and includes a very quick and fair peer-review system. Visit http://www.dovepress.com/ testimonials.php to read real quotes from published authors. 